\title{
PEDOT-PSSA as an alternative support for Pt electrodes in PEFCs
}

\author{
K K TINTULA ${ }^{\dagger}$, S PITCHUMANI ${ }^{\dagger}$, P SRIDHAR ${ }^{\dagger}$ and A K SHUKLA* \\ Solid State and Structural Chemistry Unit, Indian Institute of Science, Bangalore 560 012, India \\ ${ }^{\dagger}$ CSIR—Central Electrochemical Research Institute-Madras Unit, Chennai 600 113, India
}

MS received 27 August 2009

\begin{abstract}
Poly (3,4-ethylenedioxythiophene) (PEDOT) and poly (styrene sulphonic acid) (PSSA) supported platinum (Pt) electrodes for application in polymer electrolyte fuel cells (PEFCs) are reported. PEDOT-PSSA support helps Pt particles to be uniformly distributed on to the electrodes, and facilitates mixed electronic and ionic $\left(\mathrm{H}^{+}\right.$-ion) conduction within the catalyst, ameliorating $\mathrm{Pt}$ utilization. The inherent proton conductivity of PEDOT-PSSA composite also helps reducing Nafion content in PEFC electrodes. During prolonged operation of PEFCs, Pt electrodes supported onto PEDOT-PSSA composite exhibit lower corrosion in relation to $\mathrm{Pt}$ electrodes supported onto commercially available Vulcan XC-72R carbon. Physical properties of PEDOTPSSA composite have been characterized by X-ray diffraction, Fourier transform infrared spectroscopy, scanning electron microscopy and transmission electron microscopy. PEFCs with PEDOT-PSSA-supported Pt catalyst electrodes offer a peak power-density of $810 \mathrm{~mW} \mathrm{~cm}$ at a load current-density of $1800 \mathrm{~mA} \mathrm{~cm}$-2 with Nafion content as low as $5 \mathrm{wt}$ \% in the catalyst layer. Accordingly, the present study provides a novel alternative support for platinized PEFC electrodes.
\end{abstract}

Keywords. Poly (3,4-ethylenedioxythiophene); poly (styrene sulphonic acid); $\mathrm{H}_{2} / \mathrm{O}_{2}$ fuel cell; corrosion; Nafion content.

\section{Introduction}

Polymer electrolyte fuel cells (PEFCs) offer promise to power a variety of stationary and portable devices (Christopher and Bird 1996; Mehta and Cooper 2003; Scott and Shukla 2004). Unlike other low-temperature fuel cells, viz. alkaline and phosphoric acid fuel cells, PEFCs provide certain additional advantages such as elimination of electrolyte leakage and lower materials corrosion in addition to a simpler stack-design (Dhar 1993). In recent years, advances in PEFC electrodes have furthered the operating power-densities for PEFCs making them commercially more attractive than ever before (Gamburzev and Appleby 2002), but high manufacturing cost still remains a stigma in their commercialization. It is recently documented that the major cost of the PEFC stack comes from membrane electrolytes, electrodes and bipolar plates, and not from platinum catalyst (Meyers 2008). Various activated carbons have been used to support precious metal catalysts for many years. But carbon is thermodynamically unstable in the cathodic environment of PEFC and the presence of platinum further aggravates its corrosion (Roen et al 2004; Borup et al 2006; Dicks 2006). Accordingly, efforts are being expended to mitigate carbon corrosion through its modification, viz. by its graphitization, boron and phosphorous doping of carbon,

*Author for correspondence (shukla@sscu.iisc.ernet.in) and by use of carbon nanotubes, carbon aerogels and mesoporous carbon (McBreen et al 1981; Durkic et al 1997; Serp et al 2003; Selvarani et al 2007; Sahu et al 2009).

Alternatively, electrodes comprising composites of a conducting polymer and a poly-anion have also been reported as catalyst supports for PEFCs owing to their high electronic and proton conductivity as well as due to their permeability to reactant gases and water (Pickup et al 2000; Drillet et al 2006). In this context, substitution of carbon with conducting polymers, such as polypyrrole and polyaniline, to realize electrodes for PEFCs (Pickup et al 2000) and direct methanol fuel cells (DMFCs) has been exercised (Laborde et al 1994; Juttner et al 2004; Patra and Munichandraiah 2009). Interestingly, such electrodes require only a two-phase boundary for the operation of the fuel cell unlike the conventional fuel cell electrodes that require a three-phase interface (Qi et al 1998).

Poly (3,4-ethylenedioxythiophene) (PEDOT) is an attractive electron conducting polymer. It exhibits high electrical conductivity in its oxidized state with chemical stability under ambient conditions. As a promising conducting polymer with environmental stability and sensitivity, PEDOT is commonly used in sensors for detecting ammonia, nitrogen dioxide and other toxic organicvapours (Watanabe et al 1990; $\mathrm{Hu}$ and $\mathrm{Xu} 2000$ ). It is reported that during the synthesis of PEDOT, the solubility of 3,4-ethylenedioxythiophene (EDOT) is facilitated by the use of a water-dispersible polymer electrolyte, viz. 
poly(styrene sulfonic acid) (PSSA), which acts as a charge balancing counter-ion to form PEDOT-PSSA composite (Crispin et al 2003). Although there are reports about the use of PEDOT-PSSA as support for catalytic electrodes in various electrochemical reactions (Qi and Pickup 1998; Lefebvre et al 1999a), its usage in PEFCs and DMFCs as catalyst support is lacking. In the literature, only Drillet et al $(2006,2007)$ studied the use of pristine PEDOT both as gas-diffusion layer and catalyst support for use in DMFCs.

The present study is an effort to replace carbon with PEDOT-PSSA composite as the catalyst support to realize PEDOT-PSSA-supported Pt electrodes exhibiting mixed conduction within the catalyst layer to help attaining optimum utilization of the Pt catalyst. Platinum impregnation on PEDOT-PSSA surface has been found effective and efficient in PEFCs with stability. The substitution of carbon by PEDOT-PSSA composite is expected to prolong the durability of PEFCs. To our knowledge, the present study on PEDOT-PSSAsupported Pt electrodes for application in PEFCs is the first-ever reported in the literature.

\section{Experimental}

\subsection{Materials}

EDOT and chloroplatinic acid $\left(\mathrm{H}_{2} \mathrm{PtCl}_{6} \cdot x \mathrm{H}_{2} \mathrm{O}\right)$ were procured from Aldrich and Alfa Aesar, respectively. Sodium salt of polystyrenesulfonate (NaPSS), formaldehyde and ferric nitrate procured from Acros Organics were used asreceived, and de-ionized water (resistivity $=18 \mathrm{M} \Omega \mathrm{cm}$ ) was used during the study.

\subsection{Synthesis of PEDOT-PSSA composite}

PEDOT-PSSA composite was synthesized using the procedure described elsewhere (Qi and Pickup 1998). In brief, EDOT was polymerized by mixing an aqueous solution of NaPSS and EDOT. Initially, $0.7 \mathrm{~g}(4 \mathrm{mmol})$ of NaPSS was dissolved in $40 \mathrm{~mL}$ of de-ionized water followed by addition of $2.84 \mathrm{~mL}(20 \mathrm{mmol})$ of EDOT monomer with stirring for $30 \mathrm{~min}$. To the aforesaid admixture, $40.4 \mathrm{~g}$ of $\mathrm{Fe}\left(\mathrm{NO}_{3}\right)_{3} \cdot 9 \mathrm{H}_{2} \mathrm{O}$ dissolved in $5 \mathrm{~mL}$ of water was added drop wise under stirring at room temperature $\left(\sim 25^{\circ} \mathrm{C}\right)$. The dark-blue coloured suspension thus obtained was filtered, washed first with $0 \cdot 1 \mathrm{~N}$ nitric acid and then copiously with de-ionized water. The resultant composite was dried at $50^{\circ} \mathrm{C}$ under vacuum.

\subsection{Preparation of electro-catalyst}

$0.53 \mathrm{~g}$ of PEDOT-PSSA was added to an aqueous solution of $1 \mathrm{~g} \mathrm{H}_{2} \mathrm{PtCl}_{6} \cdot \mathrm{xH}_{2} \mathrm{O}$ under stirring for $30 \mathrm{~min}$ follo- wed by addition of $154 \mathrm{~mL}$ (38 wt.\%) aqueous $\mathrm{HCHO}$ solution. The admixture was stirred well in a roundbottom flask and refluxed at $80^{\circ} \mathrm{C}$. After cooling to room temperature, the mixture was passed through a mixedcellulose-ester membrane filter and dried at $50^{\circ} \mathrm{C}$. The dried powder was used as $40 \mathrm{wt} . \%$ Pt-supported catalyst to prepare PEFC electrodes.

\subsection{Fabrication of membrane electrode assembly (MEA)}

15 wt.\% teflonized Toray-TGP-H-120 carbon paper of $0.37 \mathrm{~mm}$ thickness was used as the backing layer. To prepare the gas-diffusion layer (GDL), Vulcan XC-72R carbon was suspended in cyclohexane and agitated in an ultrasonic water bath for $30 \mathrm{~min}$. To this solution, $15 \mathrm{wt}$ \% poly (tetrafluoroethylene) (PTFE) suspension in $2 \mathrm{~mL}$ ammonia was added with continuous agitation to form a slurry. The resultant slurry was coated on the backing layer uniformly until required loading of $1.5 \mathrm{mg} \mathrm{cm}^{-2}$ carbon was attained. GDL thus obtained was sintered in a furnace at $350^{\circ} \mathrm{C}$ for $30 \mathrm{~min}$. For the reaction layer, varying amounts of Pt-impregnated PEDOTPSSA were dispersed in ethanol and ultrasonicated for 30 min followed by the addition of varying amounts of Nafion (DuPont) solution between $5 \mathrm{wt} . \%$ and $30 \mathrm{wt} . \%$; the resultant slurry was ultrasonicated for $1 \mathrm{~h}$. The slurry thus obtained was coated onto the GDL to prepare the desired anode or cathode. A thin layer of $1: 1$ solution of 5 wt.\% Nafion and isopropyl alcohol was applied onto the surface of the electrode and the membrane electrode assembly (MEA) was obtained by sandwiching the pretreated Nafion-1135 membrane between the two electrodes followed by its hot-pressing under a pressure of $25 \mathrm{kN}\left(60 \mathrm{~kg} \mathrm{~cm}^{-2}\right)$ at $120^{\circ} \mathrm{C}$ for $3 \mathrm{~min}$.

\subsection{Physicochemical characterization}

Formation and doped states of PEDOT were confirmed by recording their Fourier-transform infra-red spectra on a Thermo Nicolet (Model Nexus 670) Spectrometer. $\mathrm{X}$-ray powder diffraction (XRD) patterns for the catalyst were obtained on a Philips Pan Analytical X-ray Diffractometer. The supported catalyst was also examined under transmission electron microscope (Model $200 \mathrm{kV}$ Tecnai-20 G2) and scanning electron microscope (Model JEOL JSM 5400 SEM). Electronic conductivity measurements were carried out on various samples in pellet form using a four-probe set up (Scientific Instruments, Roorkee, India).

\subsection{Electrochemical characterization}

2.6a Cyclic voltammetric studies: Cyclic voltammetric measurements were conducted at $25^{\circ} \mathrm{C}$ to determine the 
electrochemical surface-area for dispersed $\mathrm{Pt}$ onto PEDOT/PSSA electrode using a potentiostat (Autolab PGSTAT 30) with its reference and counter electrodes connected to the cell anode, and working electrode (Pt dispersed onto PEDOT/PSSA) to the cell cathode. During the experiment, gaseous hydrogen and gaseous nitrogen were fed to the anode and cathode, respectively. Voltammograms were recorded after a run time of $1 \mathrm{~h}$ with the working electrode cycled between $0 \mathrm{~V}$ and $1 \mathrm{~V}$ at a sweep rate of $50 \mathrm{mV} \mathrm{s}^{-1}$ to obtain stable and reproducible voltammograms.

2.6b Chronoamperometric measurements: Chronoamperometric measurements were conducted on Ptdispersed PEDOT/PSSA electrode following the procedure described elsewhere (Wang et al 2006). In brief, a three-electrode electrochemical cell was used with $\mathrm{Ag} / \mathrm{AgCl}$ as reference electrode and Pt-foil as counter electrode. The working electrodes were prepared by coating a slurry of the required amount of Vulcan $\mathrm{XC}-72 \mathrm{R}$ or PEDOT-PSSA or Vulcan XC-72R supported 40 wt.\% Pt or PEDOT-PSSA supported $40 \mathrm{wt} \% \mathrm{Pt}$ onto the teflonized Toray paper of $1 \mathrm{~cm}^{2}$. Before coating, the slurry was ultrasonically dispersed in ethanol for $30 \mathrm{~min}$. The as-prepared electrodes were immersed in $0.5 \mathrm{M}$ sulphuric acid solution and current response as a function of time was measured using a potentiostat (Autolab PGSTAT 30) at $0.9 \mathrm{~V}$.

2.6c Conductivity measurements: Ionic conductivity values were obtained by impedance spectroscopy using the procedure described elsewhere (Lefebvre et al 1999b). In a three-electrode configuration, $\mathrm{Pt}$ wire was used as the counter electrode and saturated potassium chloride calomel electrode (SCE) as the reference electrode, while working electrodes were prepared by spreading the slurry of PEDOT-PSSA-supported Pt or PEDOT-PSSA on a glassy carbon electrode. All potentials were measured with respect to SCE reference electrode, viz. $0 \cdot 244 \mathrm{~V}$, with respect to normal hydrogen electrode. All measurements were carried out using an Autolab PGSTAT 30 potentiostat with aqueous $0.5 \mathrm{M}$ sulphuric acid as electrolyte in the frequency range between $65 \mathrm{kHz}$ and $0.1 \mathrm{~Hz}$ with a perturbation amplitude of $5 \mathrm{mV}$ on a frequency response analyser (FRA) coupled to the potentiostat.

2.6d Performance evaluation of PEFCs: MEAs were evaluated in a $4 \mathrm{~cm}^{2}$ PEFC fuel cell with parallel serpentine flow-field machined on graphite plates (Schunk Kohlenstofftechnic). After equilibration, the fuel cell was tested at $60^{\circ} \mathrm{C}$ with gaseous hydrogen at anode and gaseous oxygen at cathode both under atmospheric pressure. Both the gaseous reactants were passed through humidifiers before feeding them to the cell at a constant flow rate of $1.5 \mathrm{~L} \mathrm{~min}^{-1}$ using mass-flow controllers (Aalborg Instruments and Controls, US). Galvanostatic polariza- tion data were obtained using a LCN100-36 electronic load procured from Bitrode Corporation, US.

\section{Results and discussion}

\section{$3.1 \quad F T-I R$ analysis}

FT-IR spectra for pristine PEDOT-PSSA composite and 40 wt.\% Pt-dispersed PEDOT-PSSA composite are shown in figures 1(a) and (b), respectively. Both the spectra are nearly identical suggesting PEDOT structure to be retained even after incorporating the catalyst. The presence of characteristic peaks at different vibration modes in the spectra confirms the formation of PEDOT. In the spectra, peaks at 1320 and $1520 \mathrm{~cm}^{-1}$ are due to $\mathrm{C}-\mathrm{C}$ or $\mathrm{C}=\mathrm{C}$ stretching mode of thiophene ring, while $\mathrm{C}-\mathrm{S}$ vibration modes are seen at $682 \mathrm{~cm}^{-1}, 830 \mathrm{~cm}^{-1}$ and $927 \mathrm{~cm}^{-1}$, and peaks at $1086 \mathrm{~cm}^{-1}, \quad 1132 \mathrm{~cm}^{-1}$ and $1200 \mathrm{~cm}^{-1}$ are assigned to stretching mode of ethylene di-oxy $(\mathrm{C}-\mathrm{O}-\mathrm{C})$ group (Yang et al 2007).

\subsection{XRD analysis}

Powder X-ray diffraction (XRD) pattern for PEDOTPSSA-supported catalyst is shown in figure 2 . The average particle size is determined from the peak broadening using the Scherrer equation given below:

$$
t=\frac{0 \cdot 9 \lambda}{b \cos \theta_{\mathrm{b}}}
$$

where $t$ is the crystallite size in $\AA, \lambda$ represents the wavelength (1.5406 $\AA$ for $\mathrm{CuK}_{\propto}$ radiation), $b$ the full-width at

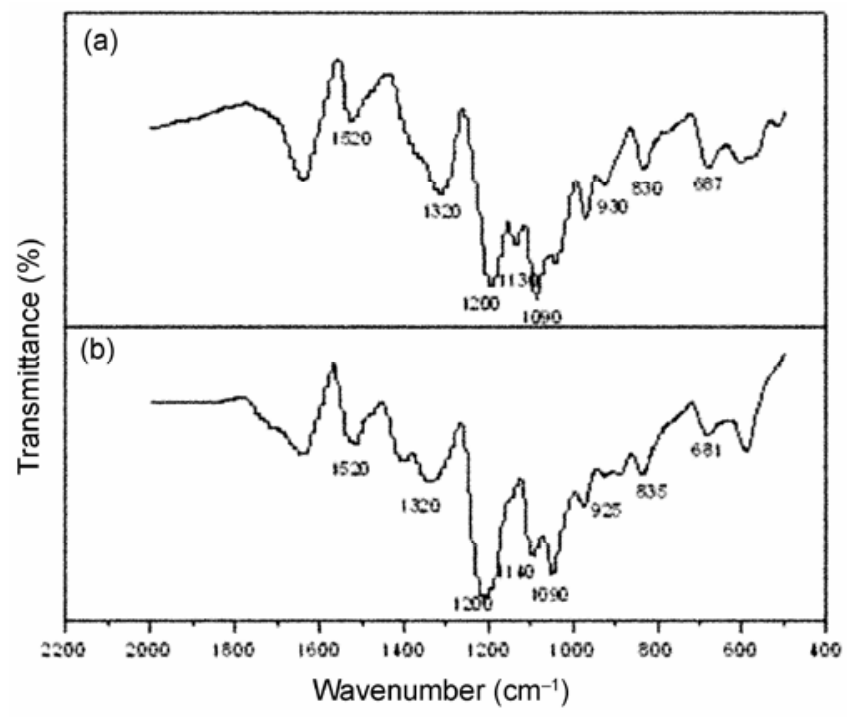

Figure 1. FT-IR spectra for (a) PEDOT-PSSA powder and (b) 40 wt.\% Pt/PEDOT-PSSA composite 


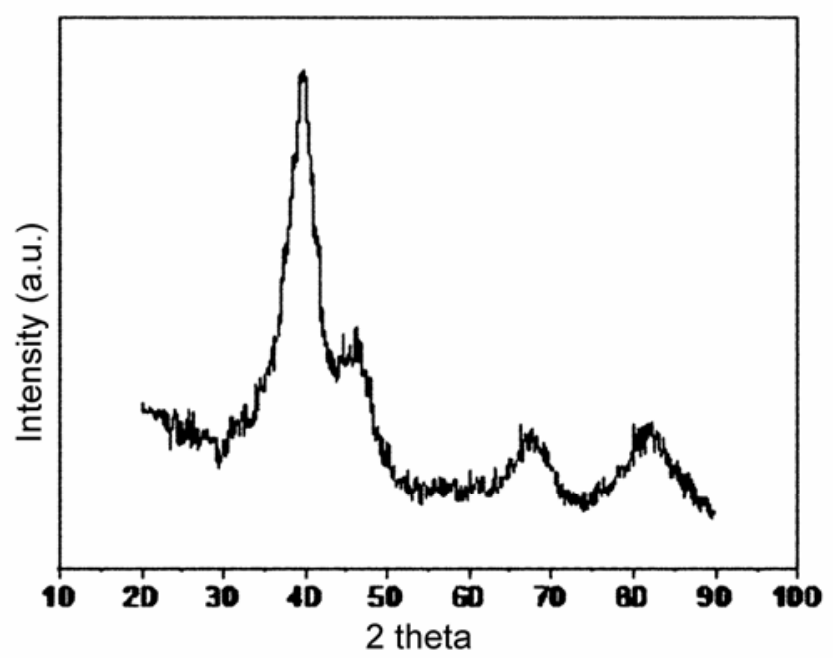

Figure 2. Powder X-ray diffraction pattern for Pt/PEDOTPSSA composite.
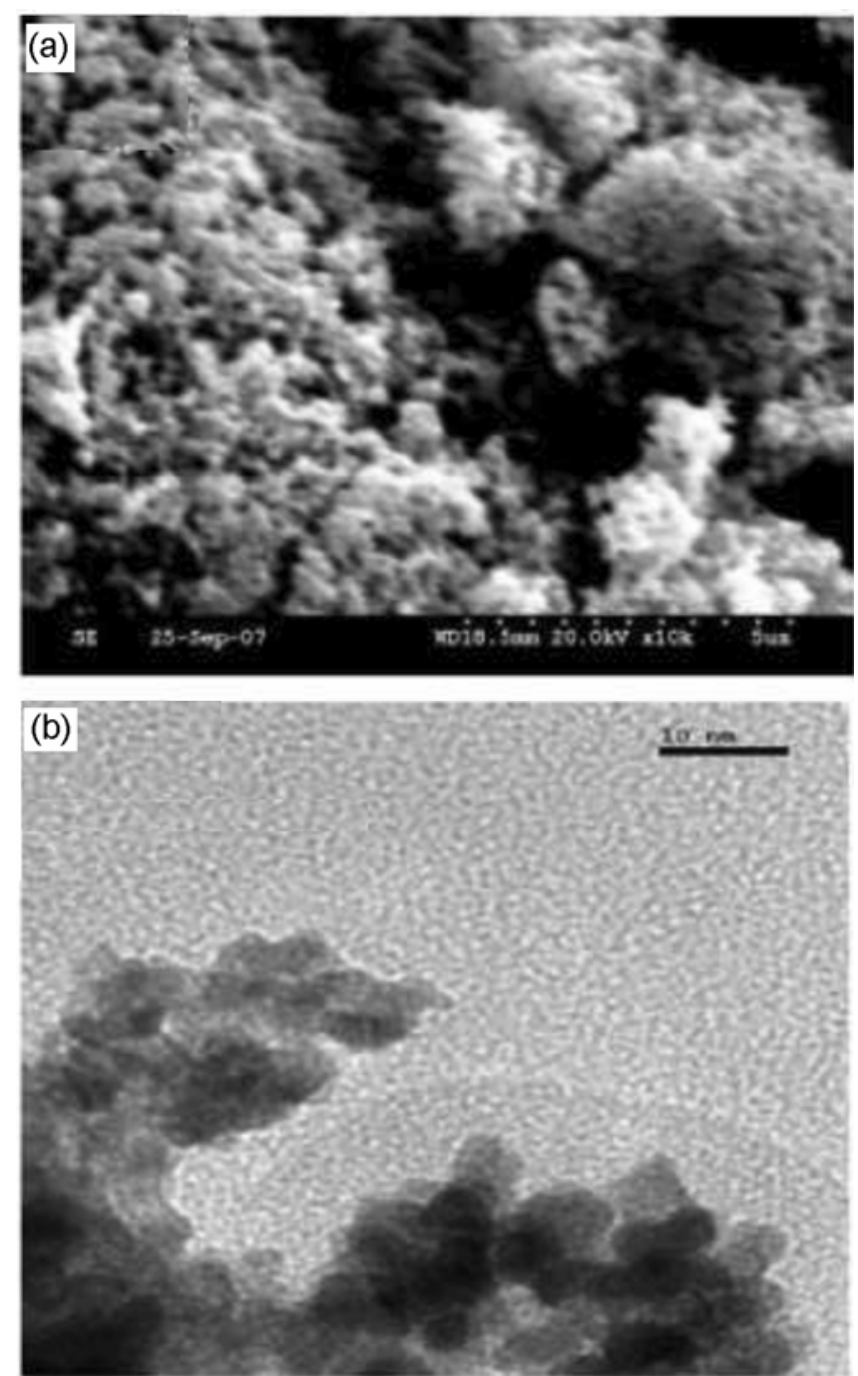

Figure 3. (a) SEM image for $40 \mathrm{wt} \%$ Pt/PEDOT-PSSA composite and (b) TEM image for 40 wt.\% Pt/PEDOT-PSSA composite. half maximum (FWHM) of a peak in the XRD pattern, and $\theta_{\mathrm{b}}$ is the diffraction angle for the peak. The dominant peaks at $2 \theta=40^{\circ}, 47^{\circ}$ and $68^{\circ}$ are due to $\mathrm{Pt}(111)$, Pt (200) and Pt (220) planes, respectively, and indicate the crystalline nature of platinum supported onto PEDOTPSSA. The average particle size for the platinum particles supported onto PEDOT-PSSA is estimated as $7 \mathrm{~nm}$ from the Pt (111) peak.

\subsection{Scanning and transmission electron microscopy (SEM and TEM) data and its analysis}

Figure 3(a) shows scanning electron micrograph for Pt-dispersed onto PEDOT-PSSA and is indicative of a particulate morphology on the base polymer-matrix suitable for effective dispersion of $\mathrm{Pt}$ in the polymer matrix and is further corroborated by its TEM picture shown in figure 3(b). It is seen that PEDOT-PSSA supports Pt particles of $<10 \mathrm{~nm}$ uniformly as desired for the fuel cell electrodes.

\subsection{Cyclic voltammetric studies}

Catalytic effect of platinum on polymer support is evaluated by cyclic voltammetric studies (Kuo et al 2006). The electrochemical surface area (ESA) of Pt catalyst is estimated using (2)

$$
\mathrm{ESA}=\frac{Q_{\mathrm{H}}}{A \times 210 \times L},
$$

where $Q_{\mathrm{H}}$ is the charge of hydrogen desorption in $\mu \mathrm{C} \mathrm{cm}^{-2}$ and $A$ the area of the electrode in $\mathrm{cm}^{2} ; 210 \mu \mathrm{C} \mathrm{cm}^{-2}$ is

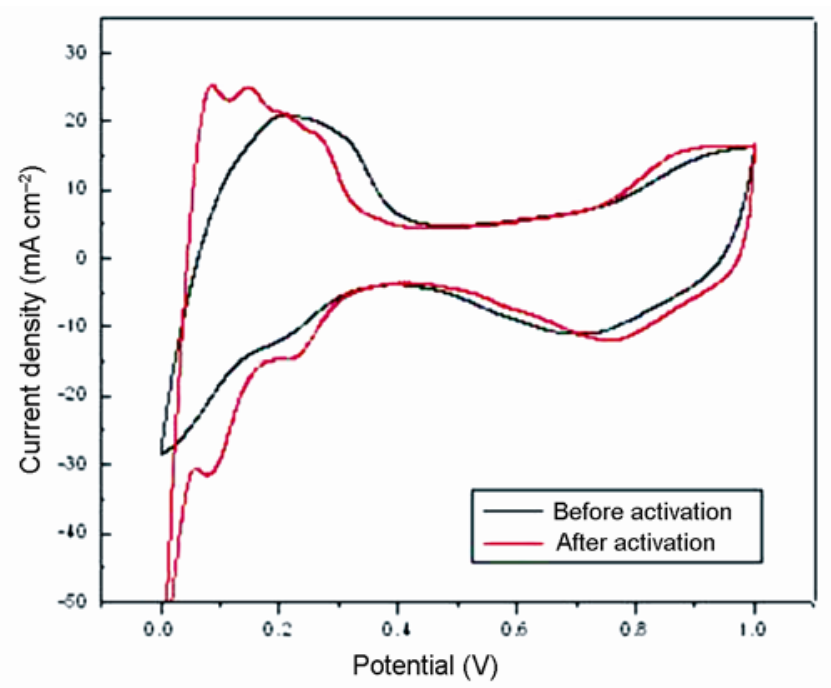

Figure 4. $\mathrm{CVs}$ for $\mathrm{Pt} / \mathrm{PEDOT}-\mathrm{PSSA}$ recorded at $25^{\circ} \mathrm{C}$ in a single cell with $\mathrm{H}_{2}$ and $\mathrm{N}_{2}$ streams at anode and cathode, respectively ( $\mathrm{scan}$ rate $=50 \mathrm{mV} \mathrm{s}^{-1}$ ) before and after the galvanostatic polarization of $\mathrm{PEFC}$ at $60^{\circ} \mathrm{C}$. 
the constant charge required to oxidize a monolayer of hydrogen on smooth platinum surface and $L$ the Pt loading in $\mathrm{mg} \mathrm{cm}^{-2}$. Figure 4 shows CVs for electrodes containing PEDOT-PSSA supported Pt with $0.5 \mathrm{mg} \mathrm{cm}^{-2}$ loading before and after the activation of fuel cell. CV for electrodes containing PEDOT-PSSA supported Pt before its activation exhibits characteristic peaks for platinum and PEDOT with the hydrogen adsorption and desorption regions identifiable in the potential range between $0 \mathrm{~V}$ and $400 \mathrm{mV}$, while PEDOT polymer dominates at potential $>400 \mathrm{mV}$. A peak due to oxidation of PEDOT is

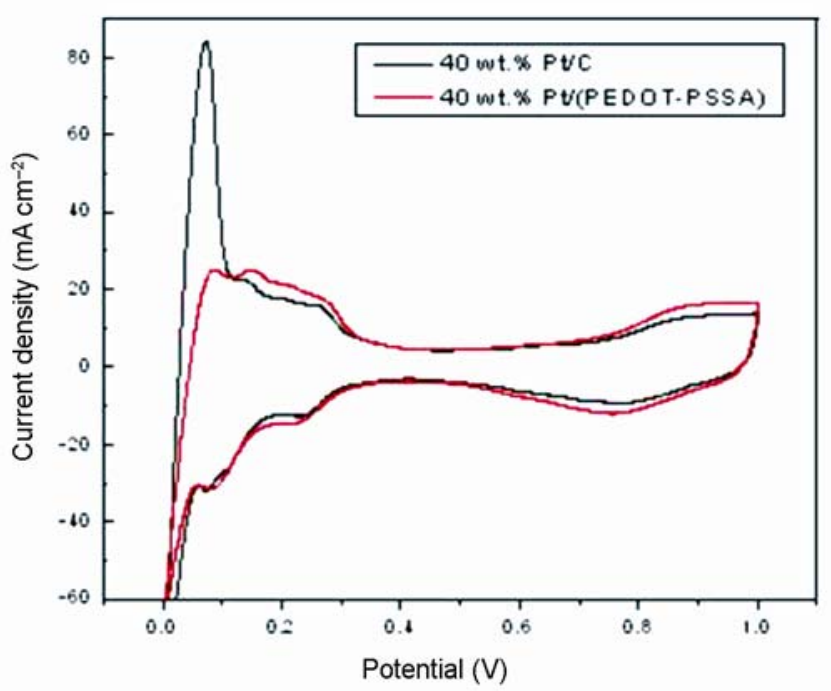

Figure 5. CVs for Pt/PEDOT-PSSA and $\mathrm{Pt} / \mathrm{C}$ in single cell mode with $\mathrm{H}_{2}$ and $\mathrm{N}_{2}$ streams at anode and cathode, respectively, at room temperature ( $\mathrm{scan}$ rate $=50 \mathrm{mV} \mathrm{s}^{-1}$ ).

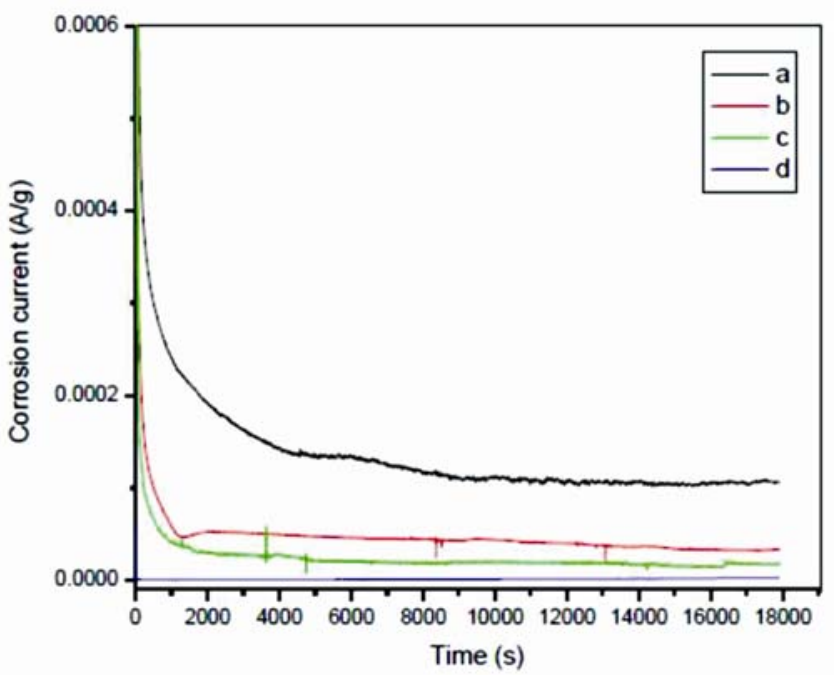

Figure 6. Chronoamperometric curves for (a) 40 wt.\% Pt/Vulcan XC-72R, (b) 40 wt.\% Pt/PEDOT-PSSA composite, (c) Vulcan XC-72R and (d) PEDOT-PSSA composite measured at $0.9 \mathrm{~V}$ in $0.5 \mathrm{M} \mathrm{H}_{2} \mathrm{SO}_{4}$. observed between $800 \mathrm{mV}$ and $1100 \mathrm{mV}$. CV for electrodes containing PEDOT-PSSA supported Pt after its activation obtained is typical of a platinum catalyst. As reported in the literature (Shan and Pickup 2000), the electrochemical response of the PEDOT support is clearly observed at platinum loadings $<30 \mathrm{wt}$. $\%$.

Figure 5 shows CVs for PEDOT-PSSA-supported Pt and commercial $\mathrm{Pt} / \mathrm{C}$ catalysts. From the hydrogen adsorption/desorption peaks between $0.0 \mathrm{~V}$ and $0.4 \mathrm{~V}$, the hydrogen adsorption charge $\left(Q_{\mathrm{H}}\right)$ for Pt/PEDOT-PSSA and $\mathrm{Pt} /$ VulcanXC-72R are found to be 94 and $107 \mathrm{mC} \mathrm{cm}^{-2}$, respectively, and the corresponding ESA values are estimated to be 90 and $102 \mathrm{~m}^{2} \mathrm{~g}^{-1}$. These data suggest: (a) the platinized surface to be unmasked by the polymer network and (b) platinized PEDOT-PSSA to be a potential catalyst for fuel cell reactions.

\subsection{Chronoamperometric studies}

Figure 6 (a-d) shows the chronoamperometric data for Pt/Vulcan XC-72R, Pt/PEDOT-PSSA, Vulcan XC-72R and PEDOT-PSSA, respectively. From these data, it is seen that PEDOT-PSSA is less corrosive than Vulcan $\mathrm{XC}-72 \mathrm{R}$. The corrosion current is only enhanced by $37 \%$ for Pt/PEDOT-PSSA in relation to $83 \%$ for $\mathrm{Pt} / \mathrm{Vulcan}$ $\mathrm{XC}-72 \mathrm{R}$. Due to oxidation of the support, noble metal particles either detach from the support or agglomerate to form larger particles affecting fuel cell performance. In pristine PEDOT-PSSA, the corrosion current may be due to the degradation of thiophene backbone in PEDOT as also due to the oxidation of remaining EDOT during the synthesis of PEDOT. Degradation of pure PEDOT has not been reported in the literature and the degradation of PEDOT-PSSA in polymer catalyst support is influenced by the presence of Pt (Roen et al 2004). But the effect of $\mathrm{Pt}$ on Vulcan XC-72R corrosion is clearly more severe in relation to PEDOT-PSSA. This suggests PEDOT-PSSA to be more corrosion resistant and durable than the conventional carbon supports used in fuel cell electrodes.

\subsection{Conductivity measurements}

Ionic conductivity values calculated following $\mathrm{Li}$ and Pickup (2000) using the low-frequency $\left(Z_{\text {low }}^{\prime}\right)$ and the high-frequency $\left(Z_{\text {high }}^{\prime \prime}\right)$ intercepts of the impedance plot with the abscissa are shown in inset to figure 3 . From $Z_{\text {low }}^{\prime}$ and $Z_{\text {high }}^{\prime \prime}$ ionic conductivity $(\sigma)$ is obtained from (3)

$$
\sigma=\frac{t}{3 A\left(Z_{\text {low }}^{\prime}-Z_{\text {high }}^{\prime \prime}\right)}
$$

where $t$ is the thickness and $A$ the area of cross-section for the sample. Figure 7 shows the ionic conductivity for PEDOT-PSSA with varying contents of Nafion. It is seen 
that higher proton conductivity is obtained for PEDOTPSSA with lower Nafion content. This is due to facilitation of proton transport along the PSSA matrix present in PEDOT-PSSA composite. However, a decrease in proton conductivity is observed for PEDOT-PSSA with higher Nafion content. This suggests that higher Nafion content blocks the pores in catalyst layer increasing the resistance of the electrode. It is noteworthy that Nafion addition is mandatory to bind electrode constituents and achieve mechanical stability. This is corroborated by fuel cell polarization studies described in $\$ 3.7$.

The data in table 1 show that custom-synthesized PEDOT-PSSA, used in this study, has ionic conductivity values similar to those reported in the literature (Ren and Pickup 1995; Lefebvre et al 1999b). There was not much change in ionic conductivity of the composite before and after its impregnation with platinum. However, there is a slight variation in the electronic conductivity values for PEDOT-PSSA and Pt/PEDOT-PSSA. This is due to the processing condition for platinum metal incorporation into the polymer matrix (Lefebvre et al 1999a). But the electronic conductivity values are still akin to conventional carbon support (Qi and Pickup 1998).

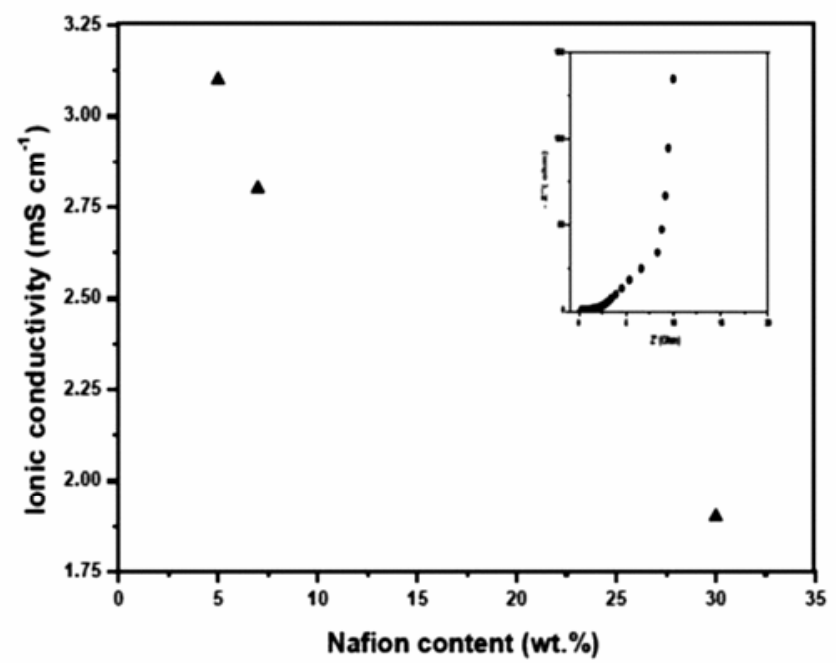

Figure 7. Ionic conductivity of electrodes containing $40 \mathrm{wt} \%$ Pt on PEDOT-PSSA with varying Nafion contents. The inset shows the impedance plot of $40 \mathrm{wt} . \% \mathrm{Pt}$ on PEDOT-PSSA between $65 \mathrm{kHz}$ and $0 \cdot 1 \mathrm{~Hz}$ in aqueous $0.5 \mathrm{M}$ sulphuric acid.

Table 1. Conductivity values for PEDOT-PSSA before and after impregnation of $\mathrm{Pt}$.

\begin{tabular}{lcc}
\hline & $\begin{array}{c}\text { Electronic } \\
\text { conductivity } \\
\left(\mathrm{S} \mathrm{cm}^{-1}\right)\end{array}$ & $\begin{array}{c}\text { Ionic conductivity } \\
\text { measured by } \\
\text { impedance spectroscopy } \\
\left(\mathrm{mS} \mathrm{cm}^{-1}\right)\end{array}$ \\
\hline PEDOT-PSSA & $8 \cdot 4$ & $3 \cdot 26$ \\
40 wt.\% Pt/PEDOT-PSSA & $4 \cdot 1$ & $2 \cdot 80$ \\
\hline
\end{tabular}

\subsection{Fuel cell performance}

Figure 8 shows the performance of $\mathrm{H}_{2} / \mathrm{O}_{2}$ PEFCs comprising anodes and cathodes containing Pt/PEDOT-PSSA with varying Nafion content between 5 wt.\% and 7 wt.\%. In the present study, the performance of PEFC comprising Pt/PEDOT-PSSA anode with 7 wt.\% Nafion and Pt/ PEDOT-PSSA cathode with 30 wt.\% Nafion is used as the reference point. Maximum peak power-densities of 810 and $740 \mathrm{~mW} \mathrm{~cm}^{-2}$ are obtained for PEFCs comprising Pt/PEDOT-PSSA electrodes with Nafion contents of 5 and 7 wt. $\%$, respectively. This suggests that higher performance observed for PEFC with electrode catalyst layer having lesser amount of Nafion is due to the presence of mixed conductivity arising due to electron and proton mobilities in PEDOT-PSSA, which help reducing the cell resistance. It is reported that performance of $\mathrm{PEFC}$ comprising electrodes with a Nafion loading $<5 \mathrm{wt} . \%$ in $\mathrm{Pt} /$ Vulcan $\mathrm{XC}-72 \mathrm{R}$ deteriorates as the three-dimensional reaction zone gets restricted to the interfaces of Nafion membrane and the catalyst layer (Sasikumar et al 2004). From the foregoing, it is clear that the mixedconductivity of the PEDOT-PSSA composite employed in this study makes it an attractive alternative to carbon commonly used in PEFC electrodes.

To study the effect of doping of PEDOT with PSSA, performance curves are obtained for PEFCs comprising electrodes with Pt/PEDOT, Pt/PEDOT-PSSA and Pt/ Vulcan XC-72R. Figure 9 shows the comparative performance curves for PEFCs with Pt supported on PEDOT, PEDOT-PSSA and Vulcan XC-72R with $7 \mathrm{wt} \%$ and 30 wt.\% Nafion on anodes and cathodes, respectively. From the data, it is seen that doping of PEDOT with PSSA shows better performance for fuel cell with a higher peak power density value $\left(605 \mathrm{~mW} \mathrm{~cm}^{-2}\right)$ compared to $\mathrm{Pt} /$ PEDOT electrode $\left(285 \mathrm{~mW} \mathrm{~cm}^{-2}\right)$ and Pt/Vulcan XC-72R

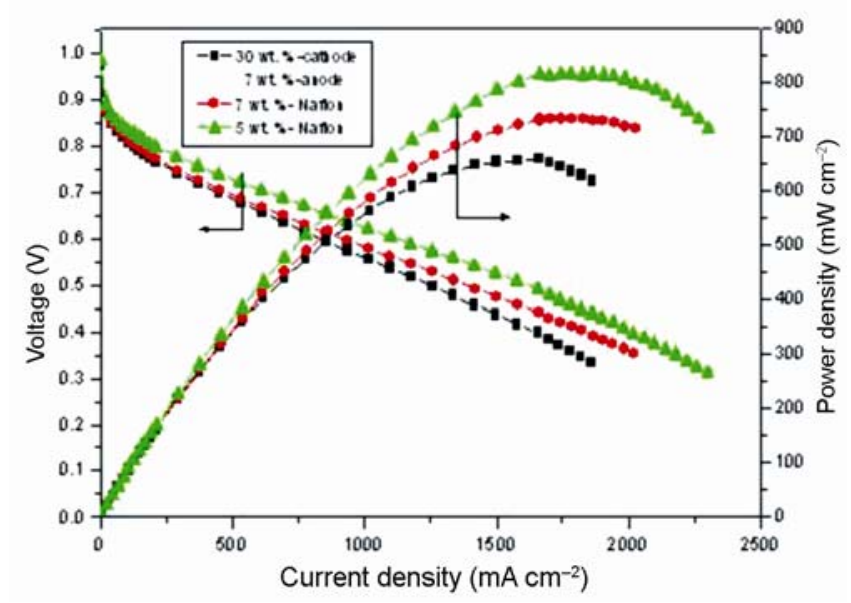

Figure 8. Performance curves for PEFCs with varying Nafion contents. 


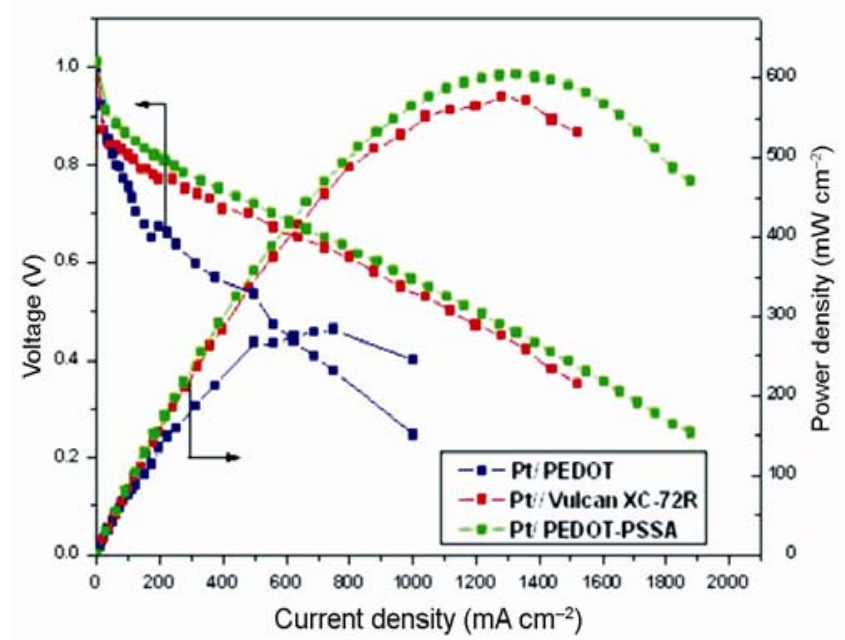

Figure 9. Performance curves for PEFCs with $40 \mathrm{wt} \% \mathrm{Pt}$ on Vulcan XC-72R, PEDOT and PEDOT-PSSA having 7 wt.\% and 30 wt.\% Nafion on anodes and cathodes, respectively.

$\left(575 \mathrm{~mW} \mathrm{~cm}{ }^{-2}\right)$. However, it is seen from figure 8 that with optimized Nafion loading, the peak power density achievable for PEFC with Pt/PEDOT-PSSA is $810 \mathrm{~mW} \mathrm{~cm}^{-2}$ compared to $575 \mathrm{~mW} \mathrm{~cm}^{-2}$ for PEFC with Pt/Vulcan $\mathrm{XC}-72 \mathrm{R}$.

The performance data for PEFCs employing Pt/ PEDOT-PSSA electrodes reported in this study is first of its kind in the literature. Earlier studies (Qi and Pickup 1998; Qi et al 1998) for oxygen reduction reaction on $37 \mathrm{wt} . \%$ Pt/PEDOT-PSSA electrodes have reported $0.4 \mathrm{~V}$ vs saturated sodium chloride calomel electrode at $300 \mathrm{~mA} \mathrm{~cm}^{-2}$ and $0.45 \mathrm{~V}$ vs NHE at $400 \mathrm{~mA} \mathrm{~cm}^{-2}$. The data presented here demonstrates a current density of $1300 \mathrm{~mA} \mathrm{~cm}$ at $0.4 \mathrm{~V}$ for a PEFC where both anode and cathode comprise Pt/PEDOT-PSSA. Accordingly, the study suggests PEDOT-PSSA composite to be a potential alternative corrosion-resistant catalyst-support material for PEFCs.

\section{Conclusions}

PEDOT-PSSA composite synthesized in this study is found to be an effective, stable and corrosion-resistant catalyst-support material for PEFCs. Its high mixed (electronic and proton) conductivity facilitates charge-transfer reactions in the catalyst layer and allows the use of electrodes with minimal Nafion content. PEFCs employing platinized PEDOT-PSSA electrodes could deliver a peak power-density of $810 \mathrm{~mW} \mathrm{~cm}$ at a load current-density of $1.8 \mathrm{~A} \mathrm{~cm}^{-2}$ while operating with $\mathrm{H}_{2}$ and $\mathrm{O}_{2}$.

\section{Acknowledgement}

Financial support from CSIR, New Delhi, under an EFYP supra-institutional project is gratefully acknowledged.

\section{References}

Borup R L, Davey J R, Garzon F H, Wood D L and Inbody M A 2006 J. Power Sources 16376

Christopher E and Bird B 1996 J. Power Sources 21497

Crispin X et al 2003 J. Polym. Sci. B41 2561

Dhar H P 1993 J. Electroanal. Chem. 357237

Dicks A L 2006 J. Power Sources 156128

Drillet J F, Dittmeyer R, Juttner K, Li L and Mangold K M 2006 Fuel Cells 6432

Drillet J F, Dittmeyer R and Juttner K 2007 J. Appl. Electrochem. 371219

Durkic T, Peric A, Lauseric M, Dukanski A, Neskovic O, Veljkovic M and Lauservic Z 1997 Carbon 351567

Gamburzev S and Appleby A J 2002 J. Power Sources 1075

$\mathrm{Hu} \mathrm{X}$ and Xu L G 2000 Polymer 419147

Juttner K, Mangold K M, Lange M and Bouzek K 2004 Russ. J. Electrochem. 40317

Kuo C W, Huang L M, Wen T C and Gopalan A 2006 J. Power Sources 16065

Laborde H, Leger J M and Lamy C 1994 J. Appl. Electrochem. 241019

Lefebvre M C, Qi Z and Pickup P G 1999a J. Electrochem. Soc. 1462054

Lefebvre M, Qi Z, Rana D and Pickup P G 1999b Chem. Mater. 11262

Li G and Pickup P G 2000 Phys. Chem. Chem. Phys. 21255

McBreen J, Olender H and Srinivasan K $1981 \mathrm{~J}$. Appl. Electrochem. 11787

Mehta V and Cooper J S 2003 J. Power Sources 11432

Meyers J P 2008 Interface 1736

Patra S and Munichandraiah N 2009 Langmuir 251732

Pickup P G, Kean C L, Lefebvre M C, Li G, Qi Z and Shan J 2000 J. New Mat. Electrochem. Systems 321

Qi Z and Pickup P G 1998 Chem. Commun. 2299

Qi Z, Lefebvre M C and Pickup P G 1998 J. Electroanal. Chem. 4599

Ren X and Pickup P G 1995 J. Electroanal. Chem. 396359

Roen L M, Paik C H and Jarvi T D 2004 Electrochem. SolidState Lett. 7 A19

Sahu A K, Nishant K G, Selvarani G, Sridhar P, Pitchumani S and Shukla A K 2009 Carbon 47102

Sasikumar G, Ihm J W and Ryu H 2004 Electrochim. Acta 50601

Scott K and Shukla A K 2004 Rev. Environ. Sci. \& Biotechnol. 3273

Selvarani G, Sahu A K, Choudhury N A, Sridhar P, Pitchumani S and Shukla A K 2007 Electrochim. Acta 524871

Serp P, Corrais M and Kalck P 2003 Appl. Catal. A253 337

Shan J and Pickup P G 2000 Electrochim. Acta 46119

Wang X, Li W, Chen Z, Waje M and Yan Y 2006 J. Power Sources 158154

Watanabe I, Hong K and Rubner M F 1990 Langmuir 61164

Yang Y, Jiang Y, Xu J and Yu J 2007 Polymer 484459 